\title{
Anomalous Difference between Hydrostatically Calculated and Directly Measured Heights Revealed by Echo-Sonde Observation
}

\author{
By S. Yoshizumi \\ Meteorological Research Institute, Tokyo, Japan \\ and \\ T. Kitaoka* \\ Katahira \& Engineers Inc. \\ (Manuscript received 28 December 1972, in revised form 20 October 1973)
}

\begin{abstract}
Comparison is made between hydrostatically calculated and directly measured heights which were obtained by echo-sonde observations There exists a large systematic height difference which has the magnitude of order of $200 \mathrm{~m}$ in the troposphere. The fact that such difference differs station to station seems to suggest that directly measured heights contain systematic error, as pointed out by Nyui and Matsuhashi (1967).

Next, characteristic features of meteorological conditions are examined in the cases where anomalous height difference was observed. It is shown that it occurs in the dry region of low Richardson number. This indicates that anomalous height difference may be associated with a wave-like disturbance in the clear atmosphere revealed by recent radar observations.
\end{abstract}

\section{Introduction}

At present, rawinsonde is widely used for upper air soundings. Usually the height at which each observation is made is not measured directly, but it is derived from simultaneous measurements of pressure, temperature and humidity through the hydrostatic assumption. By use of the heights thus determined upper air winds are computed.

However, the assumption that atmospheric stratification is in hydrostatic equilibrium is not always justified, particularly for small-scale phenomena. Thus, application of hydrostatic relationship to such situation may lead to erroneous determination of heights. For example, Davies-Jones and Ward (1971) showed that in cumulonimbus updrafts a hydrostatically calculated height may be in error by about 100 meters.

Since 1955 Japan Meteorological Agency has attempted to develop a new observation system with echo-sonde, in which the position of the sonde can be determined directly independent of measurements of pressure, temperature and humidity. This system is now used for computation of upper air winds in a part of routine

* Present affiliation: National Space Development Agency, Tokyo. observation in Japan (Suzuki, 1963; Oguma, 1971). But directly measured heights are not largely utilized except the above purpose, though they may enable us to provide further useful information. Kitaoka (1963) used echo-sonde data as an evidence of vertical air current in the stratosphere. It is, however, found that there exists an unexplained large difference between hydrostatically calculated and directly measured heights (Nyui, 1962; Nyui and Matsuhashi, 1967).

In the present paper comparison will be made between hydrostatically calculated and directly measured heights based on the data which were obtained by echo-sonde observations during the three-month period from May to July, 1971 at four aerological stations in Japan. Then, characteristic features of meteorological conditions are examined in the cases where anomalous height difference was observed.

\section{Methods of height determination and data used}

Methods of height determination. First, methods of height determination will be described briefly. Detailed description of echo-sonde observation system is given by Oguma (1971).

In the echo-sonde observation system, the 
distance between the station and the sonde, $D$, is evaluated by the measurement of the time passed from the transmission of primary radio wave at the station to the reception of the secondary wave which was emitted from the transponder borne by the balloon in response to the signal carried by the primary wave. Using the distance between the station and the sonde, $D$, thus determined, the sonde height, $H_{E}$, can be obtained without the assumption of hydrostatic equilibrium; that is, $H_{E}$ is calculated by the relationship

$$
H_{E}=\sqrt{\left(A+H_{0}+D \sin E\right)^{2}+D^{2} \cos ^{2} E}-A
$$

from the geometry. Here $A$ is the radius of the earth, $H_{0}$ the station level and $E$ is elevation angle of the sonde, which is measured by automatically tracking direction finder.

In addition, pressure, temperature and humidity are measured simultaneously with echo-sonde, which has the same sensors as those of usual radiosonde. Under the assumption that the atmosphere is in hydrostatic equilibrium, the height of $p$-mb level can be calculated, as well known, from the following integration:

$$
H_{S}=\frac{1}{g} \int_{p}^{p_{0}} \frac{R T_{v}}{p} p d+H_{0}
$$

where $p_{0}$ is the pressure at the station level, $H_{0}$, $g$ the acceleration of gravity, $R$ the gas constant for dry air, and $T_{v}$ the virtual temperature. Consequently, we can obtain hydrostatically calculated height, $H_{S}$, from eq. (2) with the aid of observed values of pressure, temperature and humidity, together with directly measured height, $H_{E}$, from eq. (1) with the aid of slant range, $D$, and elevation angle, $E$, of balloon. For brevity, $H_{S}$ aod $H_{E}$ will be hereafter called hydrostatic and echo height, respectively.

Data used. In Japan echo-sonde observations are made in a part of routine observation at Tateno, Nemuro, Akita, Hachijojima and Kagoshima of the Japan Meteorological Agency (JMA) and at Misawa of the Japan Defense Agency (see Fig. 1). Data treated in the present study are those which were obtained by echosonde observations at four aerological stations of JMA during the period from May to July, 1971. Numbers of echo-sonde ascents taken during the three-month period are listed in Table 1.

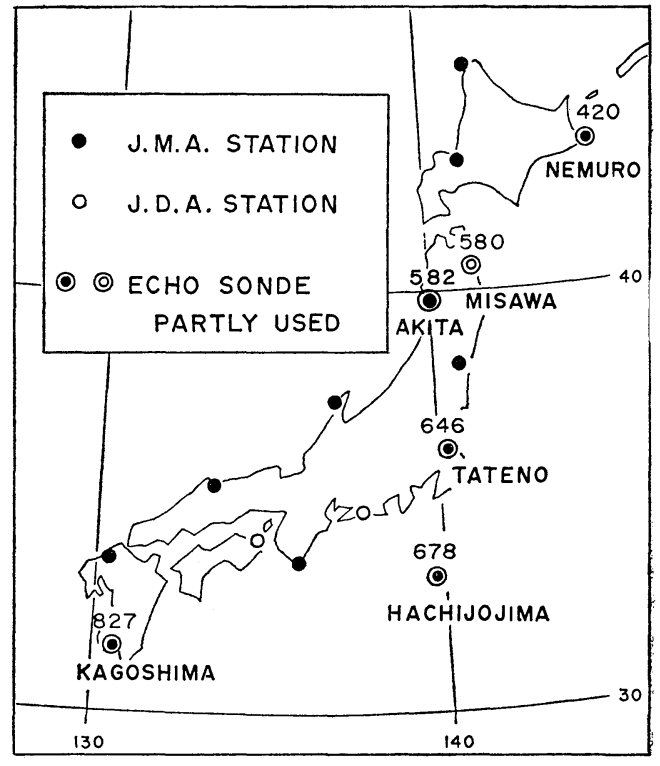

Fig. 1. Aerological stations at which echosonde observations are made.

Table 1. Numbers of echo-sonde sounding during the period from May to July, 1971

\begin{tabular}{l|r|r|r|r}
\hline & May & June & July & Total \\
\hline Nemuro & 3 & 4 & 0 & 7 \\
Tateno & 28 & 25 & 15 & 68 \\
Hachijojima & 2 & 2 & 3 & 7 \\
Kagoshima & 2 & 3 & 2 & 7 \\
\hline
\end{tabular}

In original data echo heights, $H_{E}$, are calculated at one-minute intervals during the first fourteen minutes and thereafter at two-minute intervals. Hydrostatic heights, $H_{S}$, corresponding to $H_{E}$ were interpolated through the pressure-to-time curve.

$H_{E}$ is given in geometric height, while $H_{S}$ is given in geopotential meter. But they were not reduced to the same unit because difference in numerical values due to different units does not exceed $30 \mathrm{~m}$ below the height of $12 \mathrm{~km}$ under consideration in the present study.

\section{Comparison between heights hydrostatically calculated and directly measured}

In this section comparison is made between hydrostatic and echo heights. The purpose is not to discuss in detail about the instrumental causes of height differences, but to have a general idea of accurracy of echo height measurement.

In regard to Tateno, results of comparison of 
heights were reported by Nyui (1962) and Nyui and Matsuhashi (1967). Nyui (1962) showed that at Tateno there existed a large systematic difference between both heights, which was by far larger than that due to different units. At a height of $10 \mathrm{~km}$ observed height difference was about $200 \sim 300 \mathrm{~m}$ and in the upper stratosphere echo heights had a tendency to indicate lower values than hydrostatic heights by $1 \sim 2 \mathrm{~km}$.

Further investigation was made at Tateno by Nyui and Matsuhashi (1967) who compared hydrostatic and echo heights with height determined geometrically by double theodlite observation of balloons with echo-sonde. They found out through their investigation that the distance, $D$, measured by echo system was, on the average, longer by about $100 \mathrm{~m}$ than that determined by double theodlite. On the other hand, mean difference between heights determined from hydrostatic relationship and from double theodlite did not exceed $50 \mathrm{~m}$ below the altitude of $12 \mathrm{~km}$. From these results they concluded that at Tateno mean difference between hydrostatic and echo heights in the troposphere could be ascribed to errors in distance measurement and in elevation angle, $E$, due to a little slow response of direction finder. But there still remained systematic height difference above the upper troposphere to which they could not give full explanation from the above mentioned errors.

Figs. 2a-c show the results of comparison between hydrostatic and echo heights, $H_{S}$ and for Nemuro, Kagoshima and Tateno based on the echo-sonde data during the period from May to July, 1971. The abscissa is height difference, $H_{S}-H_{E}$, and the ordinate the hydrostatic height, $H_{S}$. Our investigation was confined to the data below $12 \mathrm{~km}$ which according to Nyui and Matsuhashi (1967) may be condisered to be more reliable, since we are not interested in the instrument itself but in the relationship between the height difference and associated meteorological conditions. The solid and dashed lines in Figs. 2 denote the averaged height difference and its standard deviation over each layer $1 \mathrm{~km}$ in depth, respectively.

It is evident from these figures that the mean height difference differs from station to station. At Nemuro (Fig. 2a) directly measured heights have a tendency to indicate higher values than hydrostatically calculated ones by $100 \sim 200 \mathrm{~m}$. Systematic heigt difference at Tateno (Fig. 2c)

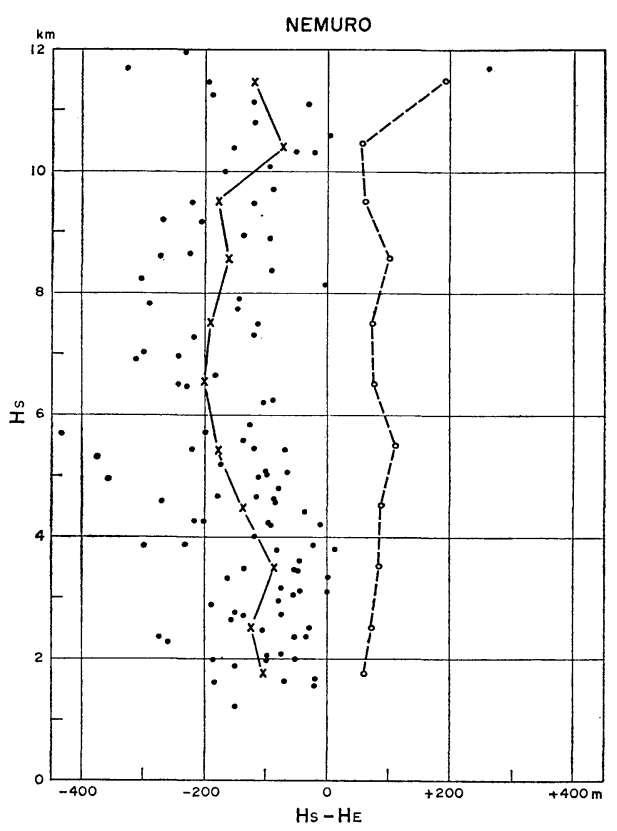

Fig. 2a. Vertical distribution of observed differences between hydrostatic and echo heights at Nemuro. Solid and dashed lines indicate the mean height difference and the standard deviation over each layer with $1-\mathrm{km}$ depth, respectively,.

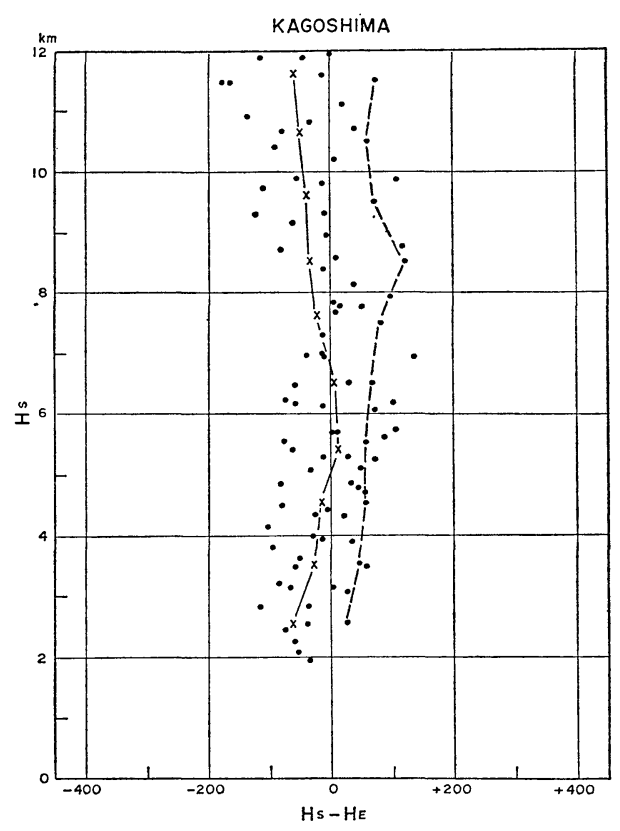

Fig. 2b. Same as Fig. 2a except for at Kagoshima. 


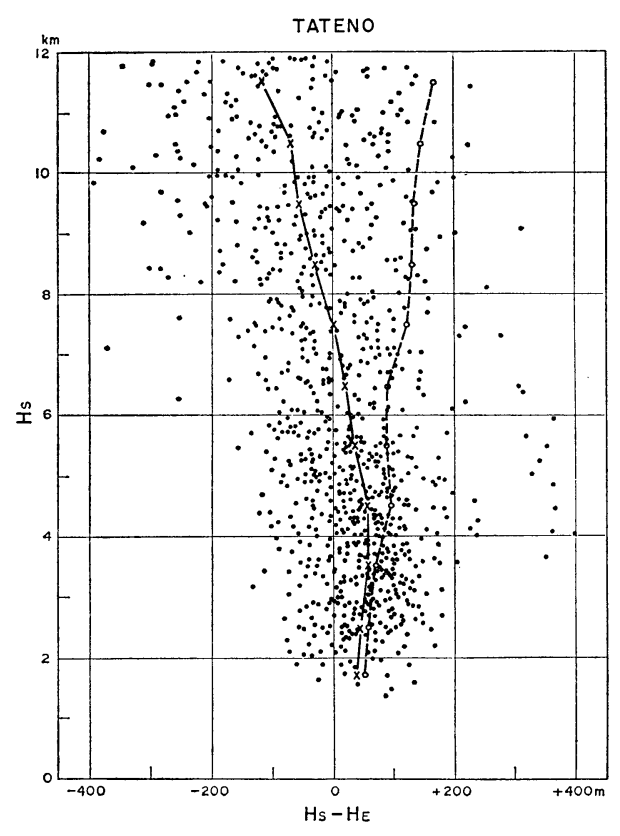

Fig. 2c. Same as Fig. 2a except for at Tateno.

seems to be very small, i.e., less than about $50 \mathrm{~m}$. Fig. $2 b$ shows at Kagoshima the mean height difference is as small as that at Tateno. However, at Kagoshima echo heights tend to be higher than hydrostatic heights, while at Tateno they tend to be lower in the lower troposphere.

It is suggested from Figs. 2a-c that systematic height difference observed at least in the troposphere is not attributed only to errors of instruments utilized for soundings. With regard to one cause of systematic height difference Yoshida (1967) scrutinized the accurracy of pressure measurement with aneroid barometer used for sonde. But it cannot be expected that such errors bring about the systematic height difference that differs from station to station because the same type of sonde is used at any station. Figs. 2 rather seem to indicate that systematic error in distance measurement may have primary contribution to mean height difference observed at other stations as well as at Tateno, as Nyui and Matsuhashi (1967) pointed out. It will be necessary to confirm this inference in future.

In Figs. 2a-c is also shown the standard deviation of height difference as a function of altitude by dashed lines. It is seen that the vertical profile of standard deviation is similar to each other, in spite of the fact that mean height difference varies from station to station. It increases gradually with increasing height, being about $50 \mathrm{~m}$ at $2 \mathrm{~km}$ and about $100 \mathrm{~m}$ at $10 \mathrm{~km}$.

\section{Estimation of vertical acceleration}

It can be demonstrated that the vertical variation of difference between hydrostatic and echo heights has a close relation to the vertical acceleration of air motion. The vertical component of equation of motion can be written in the following form:

$$
\frac{d w}{d t}=-\frac{1}{\rho} \frac{\partial p}{\partial z}-g
$$

In this equation the effect of the earth's curvature, the Coriolis force and friction are neglected. Integration of eq. (3) from $z=z_{1}$ to $z=z_{2}$ yields

$$
\left(1+\frac{1}{g} \frac{\overline{d w}}{d t}\right)\left(z_{2}-z_{1}\right)=H_{S_{2}}-H_{S_{1}}
$$

where the bar denotes a value averaged over a layer between $z_{1}$ and $z_{2}$. $H_{S_{1}}$ and $H_{S_{2}}$ are hydrostatic heights corresponding to geometric heights, $z_{1}$ and $z_{2}$, respectively. Rewriting eq. (4), we have the following relationship;

$$
\frac{1}{g} \frac{\overline{d w}}{d t}=\frac{\left(H_{S_{2}}-z_{2}\right)-\left(H_{S_{1}}-z_{1}\right)}{z_{2}-z_{1}}
$$

Thus, by using heights $H_{S}$ and $H_{E}(=z)$ obtained by echo-sonde observation, we can evaluate the vertical acceleration of air motion, which is proportional to the change rate of height difference with altitude.

Strictly speaking, it should be said that the right hand side of eq. (5) indicated roughly the extent of the deviation from hydrostatic equilibrium since the effect of the earth's curvarute, the Coriolis force and friction are neglected in eq. (3) and a sonde does not ascent exactly along the vertical. But it will be hereafter referred to, for convenience, as vertical acceleration. The effect of the horizontal drift of the sonde will be discussed in Section 6.

The histogram of vertical acceleration estimated below $12 \mathrm{~km}$ in the troposphere at Tateno during the three-month period is represented in Fig. 3. It is seen from this figure that estimated vertical acceleration has symmetric distribution around about $-0.025 \mathrm{~g}$. This bias toward negative is 


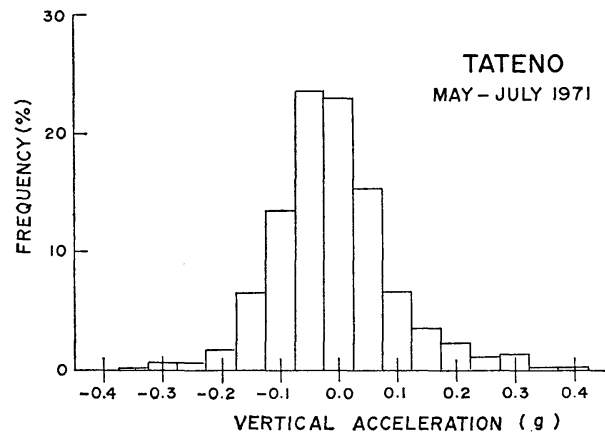

Fig. 3. Histogram of estimated values of vertical acceleration during the period from May to July, 1971 at Tateno.

ascribed to the decrease of mean height difference with increasing altitude. The standard deviation of estimated vertical acceleration is about $0.12 \mathrm{~g}$. More than 90 percent of estimated values are within the range between -0.15 and $+0.15 \mathrm{~g}$, and more than 95 percent within the range between -0.25 and $+0.25 \mathrm{~g}$.

The above standard deviation of vertical acceleration cannot be considered as realistic, since it is probably too large. It was shown in the previous section that the standard deviation of height difference was about $50 \mathrm{~m}$ in the lower layers and about $100 \mathrm{~m}$ in the upper layers. It is expected from this fact that the standard deviation of vertical acceleration is estimated to be $0.25 \mathrm{~g}$ since the thickness of layer over which it is evaluated is about $400 \mathrm{~m}$ in the lower layers and about $800 \mathrm{~m}$ in the upper layers. Therefore, estimated values from eq. (5) appear to be intensively affected by the error of height determination.

\section{Anomalous difference between hydrostatic and echo heights}

In this section we shall examine characteristic features of meteorological conditions in some cases where observed difference between hydrostatic and echo heights shows a large vertical variation with the amplitude more than $200 \mathrm{~m}$ and the magnitude of estimated vertical acceleration exceeds $0.25 \mathrm{~g}$ near the level of maximum height difference. Such vertical variation in height difference may be considered to be sufficiently significant because, as shown in the previous sections, the standard deviation of height difference and vertical acceleration were less than $100 \mathrm{~m}$ and $0.12 \mathrm{~g}$ below the



Fig. 4. 500-mb map at 0900 LST, May 20, 1971. Solid, dotted and dashed lines are contours (in $10 \mathrm{gpm}$ ), isotherms (in ${ }^{\circ} \mathrm{C}$ ) and isolines of dew point depression (in ${ }^{\circ} \mathrm{C}$ ), respectively.

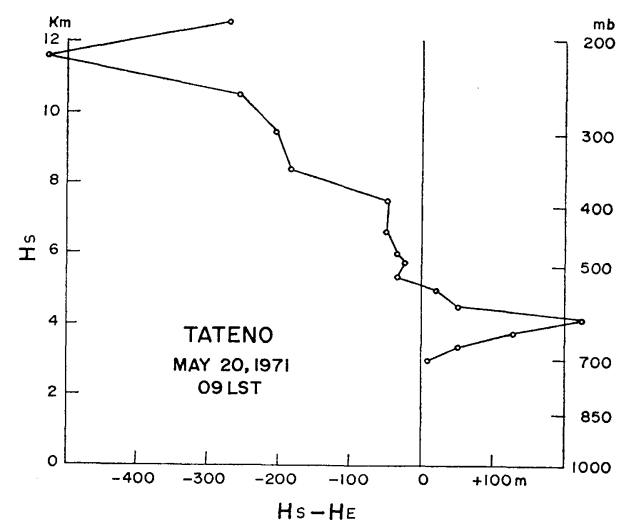

Fig. 5. Vertical profile of difference between hydrostatic and echo heights observed at Tateno at $0900 \mathrm{LST}$, May 20, 1971.

height of $12 \mathrm{~km}$, respectively.

Case I. On May 20, 1971 at Tateno. On May 20, 1971 a frontal zone went down southward, which had lain along the Japan Islands on the preceding days. Then, a migratory anticyclone, which was located in the East China Sea that day, began to cover the Japan Islands. On the $500-\mathrm{mb}$ map (Fig. 4) a cold vortex was centered on the north of Sakhalin, moving southward slowly. A very dry area with dew point depression more than $20^{\circ} \mathrm{C}$, indicative of the existence of intense downward motion, extended eastward from near the surface high in the East China Sea along the Japan Islands.

Fig. 5. illustrates the height difference as a 
function of altitude observed on May 20, 1971 at Tateno which was situated on the eastern edge of the dry area. It is noticed that rapid variations with large amplitude are superposed near $4 \mathrm{~km}$ (about $600 \mathrm{mb}$ ) and $12 \mathrm{~km}$ (about $200 \mathrm{mb}$ ) on a decreasing trend. The amplitudes of variaions exceed $200 \mathrm{~m}$ and estimated values of vertical acceleration of about $\pm 0.3 \mathrm{~g}$ are found near about $4 \mathrm{~km}$ and $12 \mathrm{~km}$, indicating sufficiently significant deviation from hydrostatic equilibrium.

Fig. 6 depicts the vertical profiles of wind, temperature and dew point temperature taken from the simultaneous sounding at Tateno. Also shown in Fig. 6 is the vertical profile of the Richardson ( $\mathrm{Ri}$ ) number that was evaluated over layers with the depth of about $800 \mathrm{~m}$. It was in a layer with intense vertical wind shear that the maximum heigdt difference at the lower level was observed. Average wind shear between 700 and $500 \mathrm{mb}$ attains $15 \mathrm{~m} \mathrm{sec}^{-1}(100 \mathrm{mb})^{-1}\left(12 \mathrm{~m} \mathrm{sec}^{-1} /\right.$ $\mathrm{km})$. As seen from Fig. 6, the temperature and dew point distributions have noteworthy features. The temperature profile indicated an adiabatic between 604 and $555 \mathrm{mb}$ (4.1 and $4.9 \mathrm{~km}$ ) above the level of maximum height difference and an isothermal between 658 and $604 \mathrm{mb}$ (3.5 and

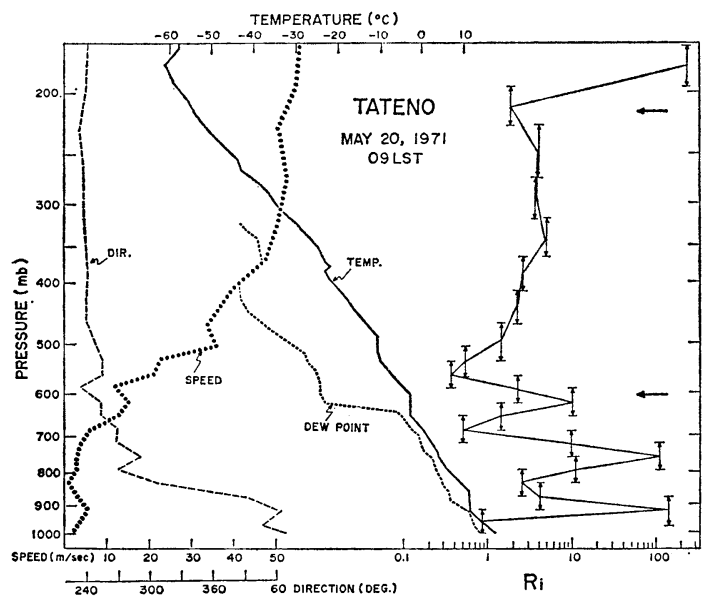

Fig. 6. Wind, temperature, humidity and $\mathbf{R i}$ number profiles at Tateno at 0900 LST, May 20, 1971. Horizontal arrow on the right indicates the level at which an extreme value of height difference was observed. Vertical arrows on the profile of $\mathrm{Ri}$ number indicate the thickness of the layer over which mean $\mathrm{Ri}$ number was estimated.
$4.2 \mathrm{~km}$ ) below. In the isothermal layer relative humidity decreases rapidly with increasing height to less than 20 percent, showing that the dry area on the $500 \mathrm{mb}$ map has a bottom at about $600 \mathrm{mb}$ over Tateno. The Ri number is estimated to be about 11 in the isothemal layer, above which it decreases to the minimum value of 0.4 in the layer 592 to $535 \mathrm{mb}(4.3$ to $5.1 \mathrm{~km})$. It is striking that anomalous height difference occurs near the layer of low $\mathrm{Ri}$ number just above the subsidence inversion.

It can also be seen from Fig. 6 that the upper anomalous height difference was observed in a layer with the minimum $\mathrm{Ri}$ number of 2.0 and strong shear of $23 \mathrm{msec}^{-1}\left(100 \mathrm{mb}^{-1}\right)\left(6.2 \mathrm{msec}^{-1}\right.$ $/ \mathrm{km})$. It is possible to find out a layer with the $\mathrm{Ri}$ number less than unity, if estimated over thinner layer, since the temperature profile indicates constant potential temperature of $338^{\circ} \mathrm{K}$ from $257 \mathrm{mb}(10.5 \mathrm{~km})$ to $227 \mathrm{mb}(11.1 \mathrm{~km})$. It is interesting that anomalous height difference occurred below the tropopause, reported to be at $182 \mathrm{mb}(12.7 \mathrm{~km})$, just south of the core of the jet stream.

Case II. On May 9, 1971 at Tateno. On May 9, 1971 Japan Islands was situated within a high pressure belt, which extended south westward from a high pressure centered in the Tohoku District. The weather was fine over a wide area along the high pressure belt. On the 500-mb map (Fig. 7) a trough, not accompanied by intense surface lows, passed over that day. On the next day a weak ridge, running after it, developed rapidly into a high with closed contours over Japan. Although the center of the surface high

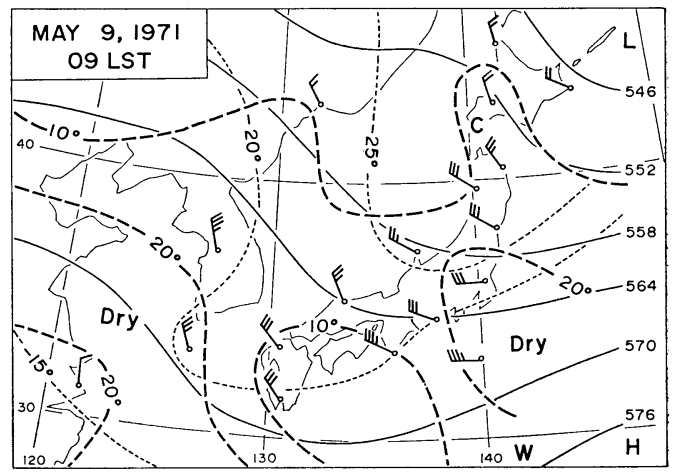

Fig. 7. Same as Fig. 4, except fdr at 0900 LST, May 9, 1971. 


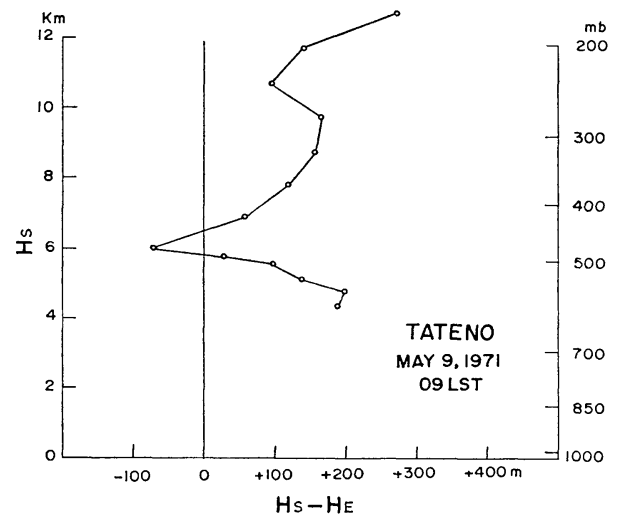

Fig. 8. Same as Fig. 5, except for at 0900 LST, May 9, 1971.



Fig. 9. Same as as Fig. 6, except for at 0900 LST, May 9, 1971.

had moved away eastward, the Japan Islands remained still under the influence of the high pressure belt during the following few days.

Fig. 8 shows the vertical profile of difference between hydrostatic and echo height observed at Tateno at 0900 LST on May 9, 1971. The profile as a whole deviates from the mean profile, shown in Fig. 2c, by about $150 \mathrm{~m}$. It should be noted here that the height difference undergoes a rapid variation at the altitude of about $6 \mathrm{~km}$, decreasing from about $+150 \mathrm{~m}$ at $5 \mathrm{~km}$ to the minimum of about $-50 \mathrm{~m}$ at $6 \mathrm{~km}$ and again increasing to $+150 \mathrm{~m}$ at $8 \mathrm{~km}$.

The vertical profiles of wind, temperature, dew point and resulting Richardson number bases on the simultaneous sounding at Tateno are represented in Fig. 9. The vertical distribution of wind

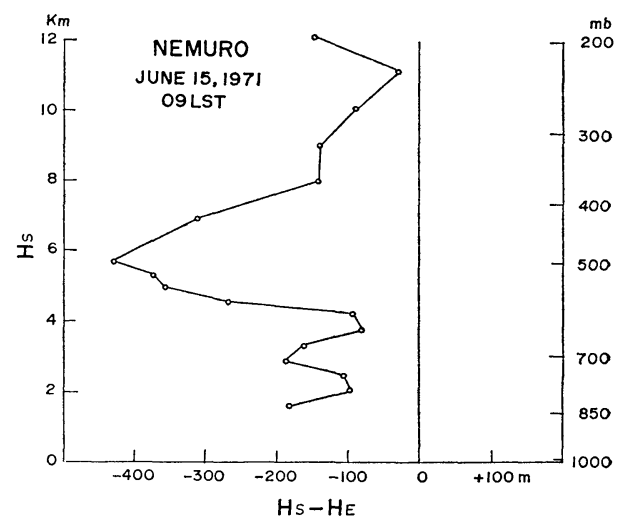

Fig. 10. Same as Fig. 4, except for at 0900 LST, June 15, 1971.

is characterized by a large wind shear near the level of the maximum height difference, though its magnitude is not so large as that in Case $\mathbf{I}$. Wind shear between 600 and $450 \mathrm{mb}$ averages $10 \mathrm{~m} \mathrm{sec}^{-1}\left(100 \mathrm{mb}^{-1}\right)\left(7 \mathrm{~m} \mathrm{sec}^{-1} / \mathrm{km}\right)$. Although the strong shear zone is not associated with a frontal zone, isentropes have a sharp slant in its vicinity. It is remarkable that the air is very dry in the middle troposphere where the large height difference was observed. A rapid decreases in relative humidity with height is recorded above a thin isothermal layer between 858 and $818 \mathrm{mb}$ $(1.4$ and $1.8 \mathrm{~km})$. The lapse rate throughout the mid and upper troposphere is considerably large; i.e., mean lapse rate from 700 to $300 \mathrm{mb}$ is about $3.4^{\circ} \mathrm{K}(100 \mathrm{mb})\left(7.7^{\circ} \mathrm{C} / \mathrm{km}\right)$. It is interesting that the level of anomalous height difference is in agreement with that in which the Richardson number reaches a minimum value of 0.6 .

Case III. On June 15, 1971 at Nemuro. The last case is one observed at Nemuro on June 15, 1971 (Fig. 10). The observed height differences below $4 \mathrm{~km}$ and above $8 \mathrm{~km}$ approximated to the mean difference shown in Fig. 2a. Between 4 and $8 \mathrm{~km}$ height difference shows a large vertical variation. A maximum deviation from the mean difference exceeds $200 \mathrm{~m}$ at about $6 \mathrm{~km}$ and near this level the height difference shows a large change rate with altitude.

In those days a high pressure belt extended east to west along the latitude circle of about $40 \mathrm{deg}$. north, and was bounded on either side by a low pressure belt along the $50 \mathrm{deg}$. lat. north and the Baiu frontal zone along the $32 \mathrm{deg}$. lat. Over the 


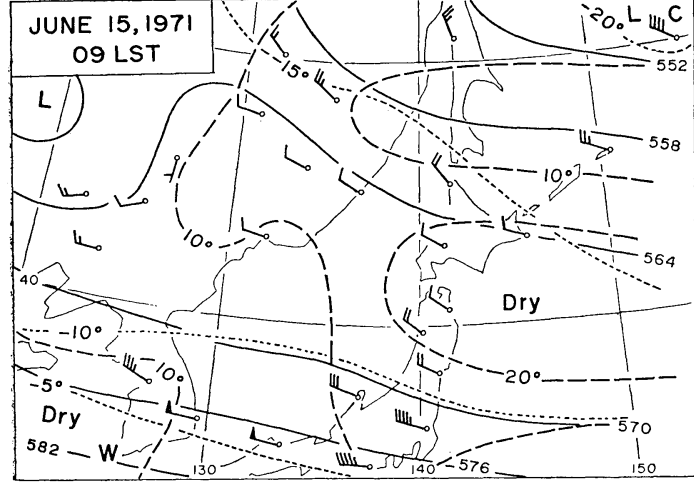

Fig. 11. Same as Fig. 5, except for at Nemuro at 0900 LST, June 15, 1971.

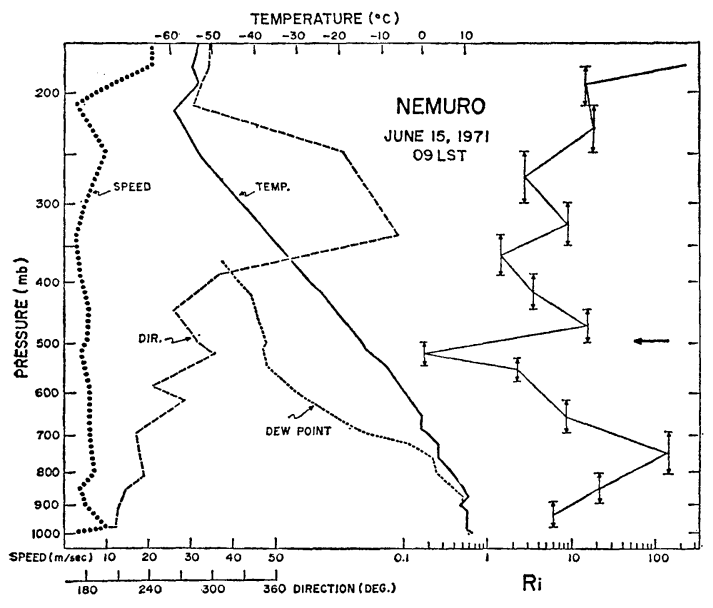

Fig. 12. Same as Fig. 6, except for at Nemuro at 0900 LST, June 15, 1971.

Hokkaido District within the high pressure belt the weather was fine, except for along the southeastern coastal area where fog or drizzle was observed. At $500 \mathrm{mb}$ (Fig. 11) a cold trough ran along 50 to $55 \mathrm{deg}$. lat. north south of a blocking high located in Siberia.

The profile of dew point temperature observed at Nemuro (Fig. 12) depicts a saturation layer below $900 \mathrm{mb}(0.9 \mathrm{~km})$ associated with drizzle near the surface and the dryness above about $750 \mathrm{mb}$ $(2.4 \mathrm{~km})$. This dry area in the mid-troposphere spreads over the Hokkaido and the Tohoku Districts and the vicinity of them (Fig. 11). There exists a zone of weak wind ruoning east in the dry area. At Nemuro within the zone of weak wind, its speeds are less than $10 \mathrm{~m} \mathrm{sec}$ throughout the troposphere, but wind direction shows large fluctuation. The sounding records a considerably rapid fall of temperature with height at an average lapse rate of $7.8^{\circ} \mathrm{C} / \mathrm{km}$ from 600 to $300 \mathrm{mb}$, especially even superadiabatic between 544 and $512 \mathrm{mb}(5.0$ and $5.5 \mathrm{~km})$. The large lapse rate and relatively strong wind shear of about $5 \mathrm{~m} \mathrm{sec}^{-1}$ $(100 \mathrm{mb})$ in the layer 520 to $444 \mathrm{mb}(5.3$ to $6.5 \mathrm{~km})$ produce a minimum of Richardson number of 0.1 near the level of anomalous height difference.

We examined meteorological conditions in three cases where a significant anomalous difference between hydrostatic and echo heights was observed. Associated meteorological features are summarized as follows; They occurred 1) in the very dry area, indicative of the area of downward motion, and 2) in a layer with large vertical wind shear. 3) A zone of low Richardson number less than unity is found out in the vicinity of the level of anomalous height difference.

\section{Discussions}

Recent radar observations have revealed that wave-like disturbances occur in the clear atmosphere (e.g., Glover et al., 1969; Browning, 1971). The wavelength and the crest-to-trough amplitude of the wave is of order of $10 \mathrm{~km}$ and of $1 \mathrm{~km}$, ressectively. Conditions of atmospheric stratification in the layer where they occur are characterized by large vertical wind shear and low Richardson number. It is also found by probing with aircraft that such disturbances have close relationship with clear air turbulence (Glover et al., 1969; Reed and Hardy, 1972).

It seems to be suggested by these facts that the observed anomalous height difference may be attributed to a wave-like disturbance as mentioned above, though no simultaneous radar observations were available in the present study. It should be noted that the observed height difference, $H_{S}-H_{E}$, has the magnitude of the order comparable to the amplitude of a wave-like disturbance detected by radar, since it can be inferred that the height difference is approximately equal to the vertical displacement of air parcel caused by the disturbance. If the phenomenon is associated with a small-scale disturbance, a pressure-to-temperature curve obtained by a sounding through it may be, of course, different from that in the undisturbed field. In the dry air the change in temperature may be considered to be under adiabatic process. Hence, the difference between temperatures in disturbed and undisturbed field is given by 


$$
\delta T=\left(\gamma-\gamma_{d}\right) \delta z
$$

where $\gamma(=-\partial T / \partial z)$ is the lapse rate in undisturbed field, $\gamma_{d}$ the dry adiabatic lapse rate, and $\delta z$ the vertical displacement of air parcel due to the disturbance. Taken $\gamma=0.7^{\circ} \mathrm{C} / 100 \mathrm{~m}$, and $\delta z=500 \mathrm{~m}$, then $\delta T=-1.5^{\circ} \mathrm{C}$. If the depth of the disturbance is taken to be $2 \mathrm{~km}$, the difference between hydrostatic heights in disturbed and undisturbed states is estimated to be at most $11 \mathrm{~m}$ from eq. (2). This means that a hydrostatic height calculated from eq. (2) has a tendency to filter out the influence of small-scale disturbance. Actually, hydrostatic heights at the station where anomalous height difference was observed are not perceived to be apparently anomalous compared with those observed at the surrounding stations. Therefore the height difference with the opposite sign, i.e., $H_{E}-H_{S}$ may be considered to represent the vertical displacement of air parcel approximatelly.

Next, we shall consider the effects of the horizontal drift of balloon and time lag of measurement on the estimation of vertical acceleration by means of eq. (5), as suggested in Section 4. If observed height difference at the time $t$ and $t+\Delta t$ are denoted by $\delta H_{1}$ and $\delta H_{2}$, respectively, the following relationship between them holds;

$$
\delta H_{2}-\delta H_{1}=\frac{\partial \delta H}{\partial z} \cdot \Delta z+\left(\frac{\partial \delta H}{\delta t}+U \cdot \frac{\partial \delta H}{\partial x}\right) \Delta t
$$

where $U$ is the speed of air current, with which the balloon is drifted horizontally, $\Delta z$ the vertical displacement of the balloon during the time period, $\Delta t$; that is, $\Delta z / \Delta t$ is the ascent rate of the balloon. Here for the sake of simplicity, it is assumed that $\delta H$ is in dependent of $y$-direction. Dividing by $\Delta z$ and substiting eq. (5), we obtain the relationship

$$
\begin{gathered}
\left(\frac{1}{g} \frac{\overline{d w}}{d t}\right)_{\text {observed }}=\left(\frac{1}{g} \frac{\overline{d w}}{d t}\right)_{\text {true }} \\
+\left(\frac{\partial \delta H}{\partial t}+U \cdot \frac{\partial \delta H}{\partial x}\right) /\left(\frac{\Delta z}{\Delta t}\right)
\end{gathered}
$$

Here the second term on the right hand side of eq. (8) stands for the effects of the horizontal drift of the balloon and time lag of measurement. If the disturbance assumes the sinusoidal form with the phase speed, $C$, and the wavelength, $L$, i.e.,

$$
\delta H=\delta H_{\max } \cdot \sin \frac{2 \pi}{L}(x-c t)
$$

the second term of the right hand side of eq. (8) can be rewritten as follows:

$$
(U-C) \cdot \frac{\partial \delta H}{\partial x} /\left(\frac{\Delta z}{\Delta t}\right)
$$

Hence

$$
\left|(U-C) \cdot \frac{\partial \delta H}{\partial x}\right|\left(\frac{\Delta z}{\Delta t}\right)\left|\leq \frac{2 \pi}{L} \delta H_{\max }\right| U-C \mid\left(\frac{\Delta z}{\Delta t}\right)
$$

Since a wave-like disturbance detected by radar propagates with a speed approximately equal to the mean wind speed in its vicinity where vertical shear is generally very strong, $|U-C|$ may be taken as $5 \mathrm{msec}^{-1}$. Substituting typical values of $0.5 \mathrm{~km}$ aod $20 \mathrm{~km}$ for $\delta H_{\max }$ and $L$, respectively, and about $400 \mathrm{mmin}^{-1}$ for $\Delta z / \Delta t$, we have

$$
\left|(U-C) \frac{\partial \delta H}{\partial x} /\left(\frac{\Delta z}{\Delta t}\right)\right| \leq 0.5
$$

This result means that the effects of the horizontal drift of the balloon and time lag of measurement are not negligible on the estimation of vertical acceleration by means of eq. (5), and suggests therefore that the values of $0.3 \mathrm{~g}$ obtained in Section 4 may be overestimated due to such effects as well as due to the error of height determinations.

The present study suggests that anomalous difference between hydrostatically calculated and directly measured heights observed by echo-sonde is associated with an atmospheric phenomenon such as a wave-like disturbance revealed by radar observation. However, in order to confirm it, it will be necessary to make a simultaneous observation with echo-sonde and radar.

\section{Acknowledgements}

The authors would like to express their hearty thanks to Mr. K. Nyui and the staff members of Aerological Observatory at Tateno and of Aerological Division of JMA for the arrangement of data. They are also indebted to Mrs. 
K. Sakurai for invaluable assistance and to Miss

H. Imai for drafting the figures.

\section{References}

Browning, K. A., 1971: Structure of the atmosphere in the vicinity of large-amplitude Kelvin-Helmholtz billows. Quart. J.Roy. Meteor. Soc., 97, 283-299.

Davies-Jones, R. P., and N. B. Ward, 1971: Comments on "Some aspects of a severe right-moving thunderstorm deduced from mesonetwork rawinsonde observations." J. Atmos. Sci., 28, 652-653.

Glover, K. M., et al., 1969: Simultaneous radar, aircraft and meteorological investigations of clear air turbulence. J. Appl. Meteor., 8, 634-640.

Kitaoka, T., 1963: Some considerations on the stratospheric circulation, related to the cause of the Aleutian high. Meteor. Abhand., 36, 121-152.
Nyui, K., 1962: Comparison of heights obtained by echo-method and sonde-method. J. Meteor. Res., 14, 849-851. (in Japaneses.)

$\longrightarrow$, and S. Matsuhashi, 1967: Report of double theodlite observations (Tsukuba-Tateno) of echosondes. J. Meteor. Res., 19, 654-676. (in Japanese.)

Oguma, K., 1969: Koso Kisyo Kansoku Sochi. Kisyo Kenkyu Noto, 99, 1-150. (in Japanese.)

Reed, R. J., and K. R. Hardy, 1972: A case study of persistent, intense, clear air turbulence in an upper level frontal zone, J. Appl. Meteor., 11, 541-549.

Suzuki, S., 1963: On new observation equipment of upper wind. Tenki, 10, 25-32. (in Japanese).

Yoshida, M., 1967: On the accuracy of echo-sonde observation (lst report) - comparison of heights obtained by echo-method and sonde-method. $J$. Meteor. Res., 19, 677-690. (in Japanese.)

\title{
エコーソンデによる静力学的算定高度と直接測定高度との異常な差
}

\author{
吉 住 禎 夫・北 岡 龍 海* \\ 気象研究所 片平エンジニアリング株式会社
}

エューゾンデ観測により得られた静力学的算定高度と直接測定された高度との比較を行う. 両者間に系統的な差が 存在し, 対流圏内では $200 \mathrm{~m}$ の大きさである。系統的な高度差は観測点により違い, このことは, 乳井と松橋 (1967) によって指摘されているょうに，直接測定値に系統的な誤差が含まれていることを示唆しているようである.

異常な高度差が観測された場合の気象条件の特赦を調べると, リチャードソン数の小さな乾燥域で起っていること が示される。このことは，異常な高度が最近のレーダー観測により晴天中に見出される波動じょう乱に伴うものであ る可能性を示唆する. 